\title{
Orientação para o Mercado Externo: Teste de um Modelo no Brasil e sua Aplicação a uma Amostra de Empresas Exportadoras Brasileiras
}

\author{
Andrea Pereira Macera \\ André Torres Urdan
}

\begin{abstract}
Resumo
Este artigo buscou investigar a Orientação para o Mercado Externo de uma amostra de empresas exportadoras brasileiras. Aplicou-se a escala multi-itens proposta por Cadogan et al. (1999) no Brasil, verificando-se seu ajustamento. Os resultados mostraram que esta pode ser considerada satisfatória quanto à: a) fidedignidade (a escala deve produzir resultados consistentes em medições repetidas); b) dimensionalidade (a Orientação para o Mercado Externo tem quatro dimensões); c) validade convergente (alta correlação entre medidas diferentes de um constructo). Contudo, a validade discriminante foi parcialmente satisfatória, sugerindo que podem haver métodos melhores de mensuração das dimensões Inteligência de Exportação e Disseminação de Informações. Do mesmo modo, foi parcial a validade nomológica, isto é, a correlação entre a Orientação para o Mercado Externo e o Desempenho Exportador. Apesar das limitações do modelo, calculou-se a Orientação para o Mercado Externo das empresas da amostra brasileira. Estas apresentaram escores superiores à média.
\end{abstract}

Palavras-chaves: escala; orientação para o mercado externo; exportação; Brasil

\begin{abstract}
The purpose of this paper is to investigate the Export Market Orientation of a sample of Brazilian exporters. The multi-item scale proposed by Cadogan et al. (1999) was applied in Brazil and its adjustment assessed. The results provided support for: a) reliability (internal consistency of the scale); b) dimensionality (the Export Market Orientation construct has four dimensions); c) convergent validity (high correlations among independent measures of the construct). However, evidence for discriminant validity was partially provided, suggesting that it might exist better measures for the dimensions Export Intelligence and Dissemination. Similarly, only partial evidence was provided for nomological validity, that is, the correlation between Export Market Orientation and Export Performance. Despite the limitations of the model, the score of Export Market Orientation was calculated for the Brazilian sample. Brazilian exporters scored above the average.
\end{abstract}

Key words: scale; export market orientation; export; Brazil. 


\section{INTRODUÇÃO}

A política comercial brasileira tem longa tradição de forte interferência governamental. Na fase do modelo de substituição de importações (1964-1985), o objetivo era impedir a entrada de produtos estrangeiros e com isso promover o desenvolvimento da indústria doméstica no Brasil. Com o propósito de estabelecer rígido controle administrativo sobre as importações e proteger os interesses locais, foi montado um esquema de subsídios e financiamentos às exportações. A partir de 1987, a opção da política econômica foi alterada, e passou-se a defender maior abertura para o exterior como forma de forçar o confronto da economia nacional com a competição internacional. Finalmente, na década de 1990, a política brasileira de abertura passou a ser elemento importante no processo de inserção na economia mundial (Papageorgiou et al., 1991). Apesar da intervenção governamental, a participação das exportações brasileiras no mundo, que era de $2,37 \%$ em 1950 , caiu para $0,88 \%$ em 2000 (MINISTÉRIO DO DESENVOLVIMENTO, INDÚSTRIA E COMÉRCIO EXTERIOR, 2002).

Tende-se a atribuir as causas desse mau desempenho às políticas governamentais. Porém, analisando-se as mudanças internacionais posteriores à Segunda Guerra Mundial (globalização e novo paradigma tecnológico), observase que uma estratégia de integração na economia mundial implica alteração de estratégia das empresas brasileiras, a fim de incorporar o mercado externo como espaço de atuação (Thorstensen et al., 1994). Ganha, então, especial destaque o conceito de Orientação para o Mercado Externo, definido como um conjunto de atividades ou comportamentos relacionados à coleta de informações sobre o mercado internacional, sua disseminação entre os vários departamentos da empresa e adoção de respostas (Cadogan et al., 1999). Nesse contexto, este artigo tem como objetivos: a) aplicar o modelo proposto por Cadogan et al. (1999) de Orientação para o Mercado Externo a empresas exportadoras brasileiras e verificar seu ajustamento; b) medir a Orientação para o Mercado Externo dos exportadores brasileiros da amostra.

O tema deste estudo é justificado por três razões em particular. Primeiro, aborda-se assunto de importância nacional, qual seja, o fraco desempenho das exportações brasileiras no cenário mundial (MINISTÉRIO DO DESENVOLVIMENTO, INDÚSTRIA E COMÉRCIO EXTERIOR, 2002), a fim de melhor compreender o problema e fornecer elementos para a busca de soluções, tanto em nível governamental quanto empresarial. Segundo, pretende- 
se contribuir para reduzir a carência de pesquisas científicas brasileiras recentes sobre o tema. Terceiro, serve-se ao desenvolvimento de escalas que operacionalizem constructos teóricos no contexto brasileiro, observando os devidos critérios de mensuração. Os pesquisadores e os praticantes brasileiros precisam deste instrumental de mensuração para aprofundar estudos sobre o tema e aplicar o conhecimento existente.

\section{Referencial Teórico}

Nos anos 90 desencadeou-se, principalmente nos Estados Unidos, uma onda de estudos sobre o constructo Orientação para o Mercado, que partiam do pressuposto de que o cliente deve ser visto como o foco das atividades empresariais. A base da Orientação para o Mercado é o próprio conceito de marketing; se a organização tem suas ações consistentes com o conceito de marketing, esta é considerada orientada para o mercado (Deshpandé, 1999, p. 5). Nesse sentido, os trabalhos desenvolvidos tinham como propósito conceituar, operacionalizar e investigar sistematicamente o constructo Orientação para o Mercado e comprovar empiricamente sua relação com o desempenho organizacional: sucesso de novos produtos, desempenho financeiro, volume de vendas, retorno sobre investimento. Destacam-se aí os trabalhos de Kohli e Jaworski (1990), Jaworski e Kohli (1993) e Narver e Slater (1990).

O primeiro estudo a chamar a atenção para a necessidade de internacionalização do constructo Orientação para o Mercado, tal qual proposto por Kohli e Jaworski (1990) e Naver e Slater (1990), foi o de Dalgic (1994). Cadogan e Diamantopoulos (1995) e Diamantopoulos e Cadogan (1996) exploraram um pouco mais a Orientação para o Mercado em contexto internacional, pois acreditavam que a simples modificação da terminologia desse constructo não seria suficiente para capturar todos os aspectos que envolvem as operações internacionais, porque o ambiente internacional difere do nacional em termos de forças políticas, econômicas, regulatórias e socioculturais.

Somente em 1999, no estudo de Cadogan et al. (1999), surgiu um modelo conceitual e operacional de Orientação para o Mercado Externo. De acordo com esse modelo a Orientação para o Mercado Externo (OME) consiste em três componentes comportamentais (Inteligência de Exportação, Disseminação de Informações e Responsividade) e de uma dimensão integrativa (Mecanismo de Coordenação). Os componentes comportamentais compreendem várias atividades associadas à geração, disseminação e formulação de respostas às informações do mercado externo e estão orientadas para os clientes, concorrentes 
e influências exógenas internacionais, como política, economia e regulação. O Mecanismo de Coordenação indica se tais atividades estão sendo conduzidas eficaz e eficientemente. Tal modelo conceitual encontra-se na Figura 1.

\section{Figura 1: Modelo de Orientação para o Mercado Externo}

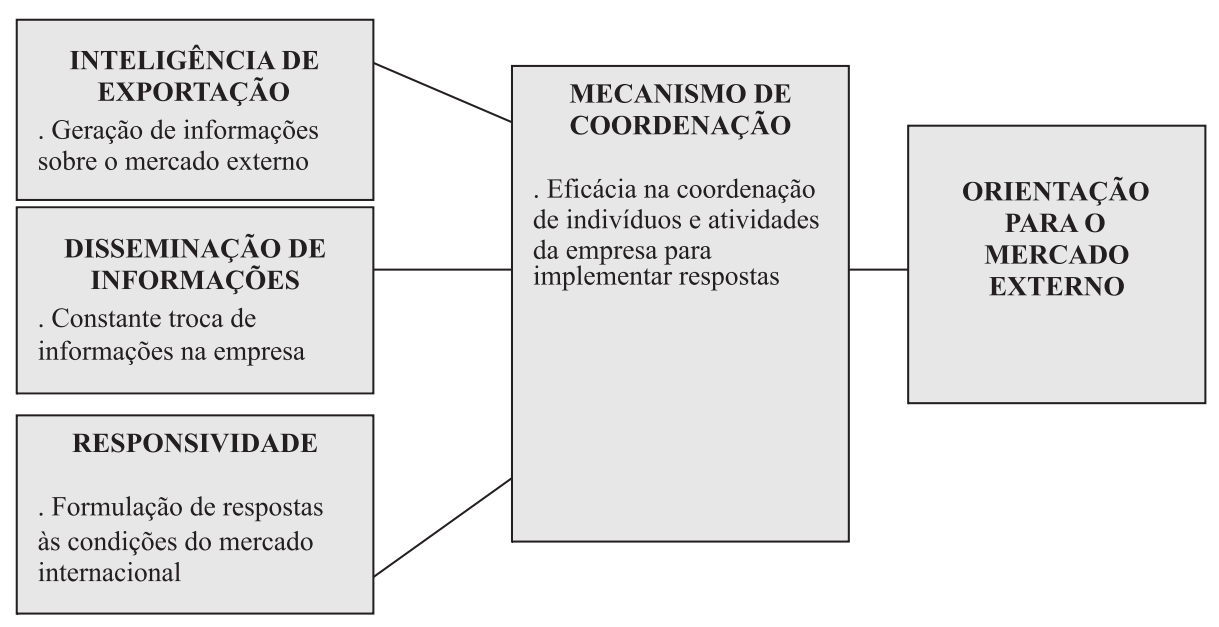

Fonte: Cadogan e Diamantopoulos (1995, p. 49).

Para operacionalizar o constructo Orientação para o Mercado Externo, isto é, desenvolver uma escala, Cadogan et al. (1999) desenvolveram um conjunto de itens a partir de uma revisão de literatura sobre o tema e entrevistas com pessoas atuantes na área de exportação. Depois, um levantamento postal abrangeu 1327 empresas exportadoras do Reino Unido e 231 empresas exportadoras da Holanda. As taxas de resposta foram $15 \%$ e $46 \%$, respectivamente. Obtidos os dados, os autores, utilizando matriz de correlação, purificaram a escala, eliminando itens pouco adequados ou negativamente correlacionados com outros. Analisaram, então, a consistência interna da escala, com o coeficiente Alfa de Cronbach, e a dimensionalidade dos itens, via fatoração por eixos principais. A validade de conteúdo foi confirmada pela revisão da literatura e pelas entrevistas. Para as validades convergente e discriminante foi utilizada a Matriz Multimétodo Multitraço (MTMM). O resultado foi satisfatório.

Finalmente, os quatro componentes da OME foram submetidos por Cadogan et al. (1999) a uma análise fatorial, para cada amostra em separado, que resultou num único fator que explica 61,9\% e 60,9\% da variância nas amostras do Reino Unido e Holanda, respectivamente. Em seguida aplicaram uma análise fatorial confirmatória, sendo a OME o constructo latente e as quatro escalas previamente 
desenvolvidas as variáveis manifestas, numa modelagem de equações estruturais. Os resultados demonstraram que a escala para quatro dimensões era adequada para mensurar o constructo OME nos dois países referidos. Ademais, ficou constatado que as medidas de OME estão correlacionadas positivamente com o desempenho exportador, o que garante a validade nomológica do modelo.

O enunciado dos itens da escala final proposta por Cadogan et al. (1999) encontra-se no Apêndice, já traduzido para o português, onde: a) as variáveis de números 1 a 11 medem o constructo Inteligência de Exportação; b) as de números 12 a 29 medem a Disseminação de Informações; c) as de números 30 a 46 medem a Responsividade; d) as de número 47 a 71 medem o Mecanismo de Coordenação. Já as variáveis de números 72 a 75 correspondem aos itens de validação utilizados na Matriz Multimétodo Multitraço.

Não se encontrou estudo brasileiro algum sobre Orientação para o Mercado Externo, pesquisando-se a Revista Brasileira de Comércio Exterior, a Revista de Administração Contemporânea, a Revista de Administração de Empresas, a Revista de Administração e os Anais do Encontro da Associação Nacional dos Programas de Pós-Graduação em Administração, no período de 1995 a 2001. Tal fato demonstra uma carência da literatura científica brasileira em comparação com a internacional. Questiona-se, portanto: $1^{\circ}$ ) se o modelo de Cadogan et al. (1999) pode ser aplicado no Brasil; $2^{\circ}$ ) se as empresas exportadoras brasileiras estão orientadas para o mercado externo. Este estudo propõe-se a contribuir para o preenchimento dessas lacunas de conhecimento.

\section{Métodos da Pesquisa Empírica}

A opção aqui foi por uma pesquisa descritiva conclusiva. Segundo Malhotra (1999, p. 84), esse tipo de pesquisa tem por base grandes amostras; além disso, a informação necessária é claramente definida e por isso a pesquisa é bem planejada e estruturada, diferindo da pesquisa exploratória. Por ser descritiva, a pesquisa busca apresentar características ou funções do mercado, e não determinar relações de causa e efeito. Devido à restrição do tempo para a conclusão da pesquisa, definiu-se um esquema de levantamento por seção cruzada única, com uma única coleta de informações de uma única amostra da população.

A população-alvo da pesquisa foi formada pelas empresas constantes do Catálogo de Exportadores Brasileiros (CEB), disponível na Internet no endereço www.cin.org.br. O Catálogo apresentava um total de 4667 empresas, em novembro de 2000 (data em que a amostra foi tomada), dividido de acordo com 
as seguintes faixas de faturamento anual com exportações: a) até US\$ 1 milhão - com 2498 empresas; b) de US\$ 1 a 10 milhões - com 1505 empresas; c) de US\$ 10 a 50 milhões - com 477 empresas; d) acima de US\$ 50 milhões - com 187 empresas.

Optou-se por incluir na amostra elementos de todas as quatro faixas de faturamento com exportação, sem discriminá-los por características da empresa, como tamanho ou tempo de atuação no mercado internacional. Para compor a amostra, foi primeiro utilizada a técnica sistemática de amostragem probabilística. Segundo Malhotra (1999, p. 339), essa técnica permite obter uma amostra representativa e confiável da população, além de poder ser utilizada sem o conhecimento prévio da composição de seus elementos. Nas três primeiras faixas de exportação, dividiu-se o tamanho total da população de cada estrato por 200. Selecionado o ponto inicial, tomou-se cada n-ésimo elemento, até que se atingisse o total de 200 elementos na amostra em cada estrato. No caso do quarto estrato, o das empresas incluídas na faixa de exportação acima de US\$ 50 milhões, optou-se por abranger toda a população, tendo em vista que esta apresentava apenas 187 elementos. Então, a amostra inicial ficou composta com 787 empresas, distribuídas pelas quatro faixas de exportação do seguinte modo: a) até US\$ 1 milhão - 200 empresas (amostragem sistemática); b) de US\$ 1 a 10 milhões 200 empresas (amostragem sistemática); c) de US\$ 10 a 50 milhões - 200 empresas (amostragem sistemática); d) acima de US\$ 50 milhões - 187 empresas (população total do estrato).

Em 04/12/2000, o questionário foi enviado por via postal, endereçado ao presidente da empresa, com a utilização dos dados de endereço de correspondência constante do Catálogo de Exportadores Brasileiros. Juntamente com o questionário, seguiram uma carta do Coordenador de Pós-Graduação da Escola de Administração de Empresas de São Paulo da Fundação Getúlio Vargas, manifestando apoio à pesquisa e encarecendo a participação dos executivos das empresas exportadoras, e também um envelope resposta selado. Transcorridos 30 dias, foi enviada uma carta, reiterando o pedido de colaboração dos executivos para responder ao questionário. O mês de agosto de 2001 foi definido como limite para incorporação dos questionários devolvidos para fins de análise. Dentro desse prazo chegaram 118 questionários, produzindo uma taxa de retorno de $15 \%$, julgada baixa. Três razões podem explicar a baixa taxa de resposta: a) a natureza impessoal do processo de levantamento de dados; b) o tamanho relativamente longo do questionário; c) a época da remessa, dezembro, mês das festas de fim de ano.

O conteúdo do questionário utilizado foi basicamente o mesmo da pesquisa de Cadogan et al. (1999), tendo por base as variáveis constantes no Apêndice. A 
segunda parte do questionário continha itens sobre as características das empresas, e a terceira parte itens pertinentes ao desempenho exportador. Tendo em vista que o questionário original se encontrava em inglês, procedeu-se à tradução reversa. A escala do questionário foi do tipo Likert, com sete posições, indo de 1 (discorda totalmente) a 7 (concorda totalmente). O formato final do questionário foi alcançado após pré-teste, junto a três empresas exportadoras brasileiras.

\section{Resultados}

No que concerne às características da amostra final, verificou-se o seguinte: a) 55,2\% eram grandes empresas, com mais de 500 funcionários; b) $50 \%$ da amostra não exportava para mais que 10 países; c) 34\% das empresas tinham os Estados Unidos como principal mercado de exportação; d) 55\% eram empresas exportadoras de bens industriais (aqueles usados por outras organizações, isto é, produtos semi-acabados, componentes, máquinas e equipamentos); 30\% exportava bens de consumo; e 14\% exportava outros produtos, em sua maioria agrícolas.

Quanto aos indicadores de desempenho exportador, foram utilizadas três variáveis: a) o tempo de atuação (em anos) da empresa na atividade exportadora; b) o faturamento bruto das exportações (em R\$) em 1999; c) a participação das exportações no faturamento total da empresa em 1999. Observou-se que $40 \%$ das empresas da amostra final estavam no máximo há 15 anos envolvidas na atividade exportadora; 34\% faturaram mais de R \$ 50 milhões com exportações; e aproximadamente $70 \%$ obtiveram até $40 \%$ do seu faturamento bruto com exportações. Observa-se que, embora as empresas da amostra tenham tido razoável tempo de experiência em exportação, essa atividade não era sua principal fonte de faturamento. Pode-se concluir que ou estas empresas dão preferência ao mercado interno para a venda de seus produtos, ou não conseguem entrar nos mercados internacionais.

Segundo Malhotra (1999, p. 278), a característica a ser medida em uma escala multi-itens é um constructo. Neste estudo o constructo é a Orientação para o Mercado Externo, já apresentado no referencial teórico. Uma escala multi-itens deve ser avaliada pela sua exatidão e aplicabilidade, o que requer análises de fidedignidade, dimensionalidade e validade. Desse modo, a apresentação adiante da análise multivariada compõe-se dos seguintes itens: a) fidedignidade das escalas; b) dimensionalidade do constructo; c) validade do constructo; d) Orientação para o Mercado Externo de uma amostra de exportadores brasileiros. 


\section{Fidedignidade}

A fidedignidade é o grau em que uma escala produz resultados consistentes em medidas repetidas da característica, equivalente à ausência de erro aleatório. Optou-se aqui por avaliar a consistência interna com o Alfa de Cronbach, sendo essa uma maneira de verificar a fidedignidade de uma escala somatório, na qual diversos escores de itens são somados para formar um escore total. Se o constructo tiver mais de uma dimensão, o coeficiente Alfa deve ser calculado para cada uma das dimensões (Churchill, 1979). De acordo com Churchill (1979, p. 69), valores acima de 0,60 indicam alto coeficiente Alfa, isto é, os kitens testados correlacionam-se bem com os verdadeiros escores. As quatro dimensões do constructo Orientação para o Mercado Externo (Inteligência de Exportação, Disseminação de Informações, Responsividade e Mecanismos de Coordenação) apresentaram coeficientes Alfa 0,75, 0,86, 0,91 e 0,95, respectivamente; portanto, os resultados mostram que a consistência interna das escalas é satisfatória.

\section{Dimensionalidade}

Quanto à dimensionalidade, supõe-se que, numa escala somatório, os itens são unidimensionais, isto é, estão fortemente associados uns aos outros e representam um único conceito (Hair et al., 1998, p. 117). A análise fatorial presta-se à verificação da dimensionalidade de um conjunto de itens, permitindo determinar o número de fatores subjacentes. No caso de uma escala com várias dimensões, cada dimensão deve ser refletida por um fator separadamente. Os 71 itens do constructo Orientação para o Mercado Externo foram, então, submetidos a uma análise fatorial exploratória. O método de extração foi a fatoração por eixos principais, com rotação ortogonal VARIMAX. No tratamento das respostas faltantes, optou-se por considerar apenas os casos com valores válidos para todas as variáveis, o que reduziu a amostra de 118 para 104. Foi definida a extração de quatro fatores, cada um correspondente a uma das dimensões do constructo. Verificou-se que o primeiro fator explica cerca de 35\% da variância da amostra, enquanto os demais fatores explicam menos de $10 \%$. Os quatro fatores explicam apenas cerca de $50 \%$ da variância da amostra. Contudo, nas ciências sociais, onde a informação não é tão precisa quanto nas ciências naturais, não é incomum considerar soluções que contam com $60 \%$ ou menos da variância total (Hair et al., 1998, p. 104). Ademais, se forem acrescentados novos fatores, cada qual explicaria menos de 3\% da variância total da amostra; portanto há indícios de que o constructo Orientação para o Mercado Externo tenha quatro dimensões, pelo menos no domínio da amostra estudada. 
A matriz de cargas fatoriais, isto é, a correlação entre as 71 variáveis e os quatro fatores permitiu comparar a alocação dos itens na proposta de Cadogan et al., (1999) e na amostra brasileira. Para tamanhos de amostra superiores a 100, Hair et al. (1998. p. 111) sugerem que cargas fatoriais (correlação entre a variável e o fator) maiores que +/- 0,30 são o mínimo aceitável. Um valor de 0,30 traduziria aproximadamente $10 \%$ da variação do fator, ao passo que 0,70 equivaleria a cerca de $50 \%$ da variância. No total, foram 22 as variáveis que divergiram do modelo original no tocante à estrutura fatorial.

\section{Validade}

A validade da escala de um constructo diz respeito àquilo que, de fato, o instrumento está medindo. Para estabelecer a validade do constructo, deve-se determinar: a) se a escala se correlaciona com outras escalas destinadas a medir o mesmo constructo; b) se a escala se comporta como esperado. Existem quatro formas de validade: a) de conceito; b) convergente; c) discriminante; d) nomológica (Churchill, 1979).

A validade de conceito verifica se os itens gerados cobrem o domínio do constructo que está sendo mensurado. No caso deste estudo, o pré-teste foi realizado apenas com três empresas exportadoras brasileiras, não sendo suficiente, portanto, para verificar a validade de conceito no Brasil.

A validade convergente verifica o grau de correlação entre duas medidas de um mesmo conceito. Altas correlações indicam que a escala está medindo o conceito pretendido. Já a validade discriminante verifica quão distintas são duas escalas conceitualmente similares. Nesse caso, as correlações devem ser baixas, demonstrando que a escala é suficientemente diferente de outra com conceito similar (Hair et al.,1998, p. 118).

Um dos métodos utilizados para verificar as validades convergente e discriminante é a Matriz Multimétodo Multitraço (MTMM). Essa técnica requer que pelos menos dois constructos sejam mensurados por meio de pelo menos dois métodos. Para tanto, aqui foi calculado um escore para cada uma das quatro escalas das dimensões do constructo Orientação para o Mercado Externo (soma dos itens sobre o número de itens). Os itens de validação utilizados foram os de número 72 a 75, constantes do questionário, (ver Apêndice). Observaram-se correlações significativamente diferentes de zero no nível de significância de 1\%. Para cada uma das quatro dimensões do constructo Orientação para o Mercado Externo as correlações são estas: 0,61(Inteligência de Exportação); 0,61 (Disseminação de Informações); 0,71 (Responsividade); e 0,74 (Mecanismo de Coordenação). Portanto a validade convergente está presente na amostra, 
indicando que as escalas medem realmente o constructo pretendido. A Matriz Multimétodo Multitraço de Orientação para o Mercado Externo encontra-se na Tabela 1.

\section{Tabela 1: Matriz Multimétodo Multitraço de Orientação para o Mercado Externo}

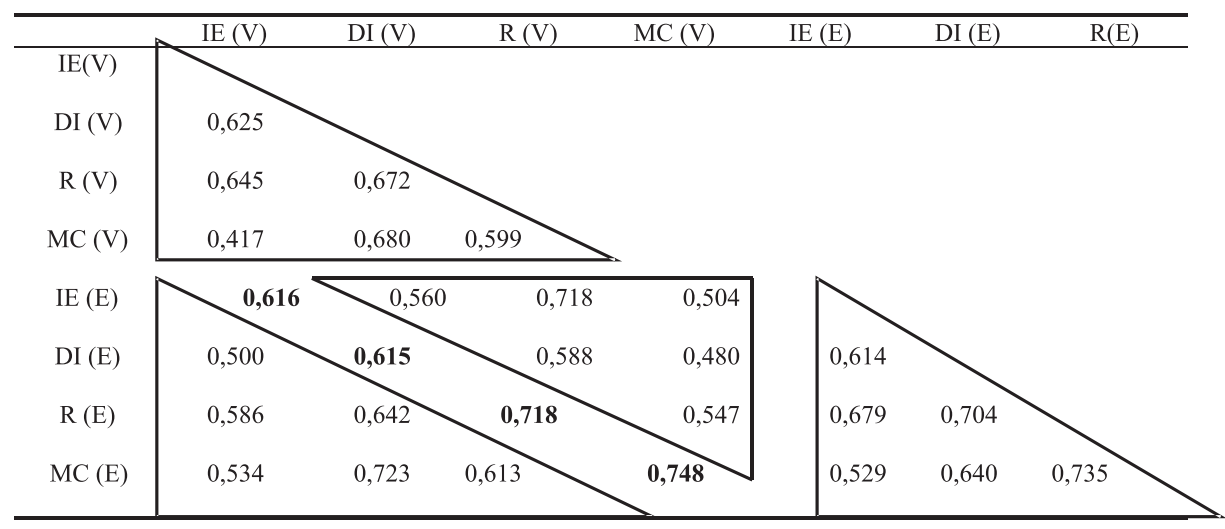

Fonte: dados da pesquisa

Legenda:

IE (V): Item de Validação da escala da dimensão Inteligência de Exportação

DI (V): Item de Validação da escala da dimensão Disseminação de Informações

R (V): Item de Validação da escala da dimensão Responsividade

MC (V): Item de Validação da escala da dimensão Mecanismos de Coordenação

IE (E): Escore da dimensão Inteligência de Exportação

DI (E): Escore da dimensão Disseminação de Informações

$\mathbf{R}$ (E): Escore da dimensão Responsividade

MC (E): Escore da dimensão Mecanismos de Coordenação

Considera-se que há evidência da validade discriminante, quando as correlações da diagonal são maiores que as correlações que ocupam a mesma linha e coluna dos triângulos superiores e inferiores. Isso significa que a correlação entre duas medidas diferentes da mesma variável deve ser maior que as correlações entre a variável e qualquer outra variável que não possua o traço nem o método em comum (Campbell e Fiske, 1959). Churchill (1979) sugere que também seja observado se os padrões de correlação entre os triângulos são os mesmos. Na Tabela 1, observa-se que os padrões de correlação são os mesmos, isto é, a correlação é positiva dentro de todos os triângulos. Contudo as correlações entre os escores médios das escalas das dimensões Inteligência de Exportação e Disseminação de Informação e seus itens de validação não são maiores que as correlações que ocupam a mesma linha e coluna nos triângulos superiores e inferiores. Isso sugere que pode haver outros métodos para medir essas duas dimensões; portanto a validade discriminante na amostra é parcial. 
Resta analisar a validade nomológica do modelo de Cadogan et al. (1999) na amostra. Segundo Churchill (1979), uma escala apresenta validade nomológica, se esta se comporta conforme o esperado em relação a algum outro constructo com o qual está teoricamente relacionada. De acordo com a literatura, há evidências de que a Orientação para o Mercado Externo seja positivamente correlacionada com o Desempenho Exportador. Uma vez que não há ainda consenso no meio acadêmico sobre qual é a melhor medida de desempenho exportador, neste estudo utilizou-se: a) o faturamento das exportações dividido pelo número de empregados da empresa, o que permite controlar diferenças no tamanho das empresas exportadoras brasileiras (medida utilizada por Cadogan et al., 1999); b) o tempo de envolvimento da empresa com a atividade exportadora; c) a participação das exportações no faturamento total da empresa. Para a Orientação para o Mercado Externo, utilizou-se um escore para cada uma das quatro dimensões como a média dos itens de cada dimensão. As respostas faltantes foram descartadas.

Foram encontradas correlações positivas entre as quatro dimensões de Orientação para o Mercado Externo e a variável participação das exportações no faturamento total da empresa, no nível de significância de 5\% ou menor. Já a variável faturamento das exportações sobre quantidade de empregados apresenta correlações significativas apenas com as dimensões Inteligência de Exportação e Disseminação de Informações. Finalmente, a variável tempo de envolvimento com a atividade exportadora não apresenta correlação positiva com dimensão alguma de Orientação para o Mercado Externo, no nível de significância de 5\% ou menor. Os resultados indicam que a relação entre Orientação para o Mercado Externo e Desempenho Exportador pode variar, dependendo de como este é mensurado. Logo, as evidências colhidas sugerem que há validade nomológica parcial do modelo de Cadogan et al. (1999).

\section{A Orientação para o Mercado Externo de uma Amostra de Exportadores Brasileiros}

Apesar de certas limitações de ajustamento do modelo de Cadogan et al. (1999) à amostra formada, sua aplicação foi mantida. Então, a fim de medir a Orientação para o Mercado Externo dos exportadores brasileiros, calculou-se um escore das quatro dimensões do constructo propostas por Cadogan et al. (1999), isto é, Inteligência de Exportação, Disseminação de Informações, Responsividade e Mecanismos de Coordenação. O escore de cada uma das dimensões foi calculado pela média, isto é, pela soma dos itens sobre o número total de itens, para reduzir o efeito das respostas faltantes. Logo, o escore máximo de cada dimensão é 7. Já o escore geral de Orientação para o Mercado Externo foi calculado pela 
média das médias das quatro dimensões, sendo seu máximo 7. A Tabela 2 apresenta as estatísticas descritivas da amostra de exportadores brasileiros em termos de Orientação para o Mercado Externo.

Quanto às dimensões do constructo, vê-se na Tabela 2 que os exportadores brasileiros da amostra apresentaram escores menores nas dimensões Inteligência de Exportação e Disseminação de Informações, com médias 4,5 e 4,6, respectivamente. Isso indica que esses exportadores não geram informações suficientes sobre o mercado externo, quando nele decidem atuar e, talvez por isso, não existe troca constante de informações dentro da empresa. A dimensão Mecanismos de Coordenação apresentou o escore mais alto $(5,5)$ entre as quatro dimensões. Esse fato, quando a empresa brasileira decide exportar, indica que ela é eficaz em coordenar os indivíduos e atividades para implementar respostas ao mercado. Ressalte-se, no entanto, que a média 5,5 apresenta certa distância do máximo, que é 7. Quanto ao escore geral de Orientação para o Mercado Externo, a Tabela 2 mostra que a média das empresas brasileiras da amostra foi 4,88, de um mínimo de 2,53 e um máximo de 6,57. Ademais, 75\% da empresas obtiveram um escore máximo de 5,62.

\section{Tabela 2: Estatísticas Descritivas da Amostra de Exportadores Brasileiros em termos de Orientação para o Mercado Externo}

\begin{tabular}{c|c|c|c|c|c}
\hline Estatísticas & $\begin{array}{c}\text { Inteligência } \\
\text { de } \\
\text { Exportação }\end{array}$ & $\begin{array}{c}\text { Disseminação } \\
\text { de } \\
\text { Informações }\end{array}$ & $\begin{array}{c}\text { Responsi- } \\
\text { vidade }\end{array}$ & $\begin{array}{c}\text { Mecanismos } \\
\text { de } \\
\text { Coordenação }\end{array}$ & $\begin{array}{c}\text { Orientação } \\
\text { para o } \\
\text { Mercado } \\
\text { Externo }\end{array}$ \\
\hline $\begin{array}{c}\text { Casos } \\
\text { válidos }\end{array}$ & 118 & 118 & 118 & 118 & 118 \\
Média & 4,5 & 4,6 & 5,0 & 5,5 & 4,88 \\
$\begin{array}{c}\text { Desvio- } \\
\text { padrão }\end{array}$ & 1,0 & 1,0 & 1,1 & 1,0 & 0,88 \\
Mínimo & 1,5 & 1,8 & 2,1 & 2,2 & 2,53 \\
Máximo & 6,7 & 6,3 & 6,8 & 7,0 & 6,57 \\
$\cdots$ & & & & & 4,24 \\
Percentis & 3,9 & 3,9 & 4,4 & 5,0 & 4,90 \\
$25 \%$ & 4,5 & 4,7 & 5,1 & 5,6 & 5,62 \\
$50 \%$ & 5,3 & 5,3 & 5,8 & 6,3 & \\
$75 \%$ & 5 & & & \\
\hline
\end{tabular}

Fonte: dados da pesquisa. 
Para que se possa fazer inferências válidas sobre a população a partir de uma amostra, é preciso que esta seja representativa. Uma das formas básicas de se conseguir representatividade é fazer com que a amostra seja aleatória. Embora a amostra inicial tenha sido extraída de modo aleatório, a amostra final terminou bem menor que a inicial. Procedeu-se, então, ao teste $t$ de diferença de médias para as quatro dimensões do constructo Orientação para o Mercado Externo entre o primeiro e último quartil da amostra (os 30 primeiros questionários recebidos e os 30 últimos, respectivamente). Os resultados não indicaram diferença significativa entre as médias, com nível de significância inferior a 5\%.

\section{Conclusões}

No que concerne aos critérios de ajustamento do modelo à amostra brasileira, esses podem ser considerados satisfatórios quanto ao seguinte: a) fidedignidade das dimensões (a escala deve produzir resultados consistentes em medições repetidas); b) dimensionalidade (a Orientação para o Mercado Externo tem quatro dimensões); c) validade convergente (as escalas medem o constructo pretendido). Contudo a validade discriminante foi parcialmente satisfatória, sugerindo que pode haver métodos melhores de mensuração das dimensões Inteligência de Exportação e Disseminação de Informações. Do mesmo modo, foi parcial a validade nomológica, isto é, a correlação entre a Orientação para o Mercado Externo e o Desempenho Exportador.

Quanto à Orientação para o Mercado Externo das empresas brasileiras da amostra, verificou-se que, entre as quatro dimensões deste constructo, os menores escores foram obtidos em Inteligência de Exportação e Disseminação de Informações. Tal resultado parece indicar que as empresas brasileiras não exportam por razões estratégicas de crescimento e diversificação de mercados, o que requer pesquisa de mercado prévia, mas por motivos tais como a saturação do mercado doméstico, incentivos governamentais ou recebimento de pedidos ou oportunidades inesperadas. No entanto, quando a empresa decide exportar, ela é eficaz em coordenar indivíduos e implementar respostas ao mercado. De modo geral, as empresas da amostra apresentaram nível médio e alto de Orientação para o Mercado Externo; o resultado é um tanto quanto surpreendente, tendo em vista a baixa participação de mercado das exportações brasileiras no mundo.

Diante das limitações parciais de ajustamento do modelo analisado, emergem duas implicações. De um lado, há a perspectiva de que testes estatísticos podem 
ser uma ferramenta algo pobre para escolher-se um modelo. Por conseguinte, no melhor dos casos, o modelo pode ser uma aproximação e, como tal, pode ser útil sem ser plenamente verdadeiro. Não sendo nunca perfeitos, os modelos podem ser rejeitados por critérios estatísticos, mas nem por isso se tornam condenados para utilização. Prevalecendo esse raciocínio, não haveria motivo para deixar de usar o modelo em pauta, já que ele apresenta a substantiva vantagem de permitir a mensuração da Orientação para o Mercado Externo de praticamente qualquer empresa e ramo no Brasil, além da eventual comparação (benchmarking) com os níveis respectivos de empresas de países desenvolvidos, mormente dos Estados Unidos.

De outro lado, as opções seriam estas duas: a) iniciar a concepção de um modelo a partir da estaca zero, tendo por substrato as especificidades da realidade brasileira; b) tentar modificar o modelo de forma incremental, melhorando seu ajustamento aos dados (Hair et al., 1999). Numa modalidade ou na outra perderse-ia a atraente possibilidade de comparação com empresas no exterior, aplicando a escala de Cadogan et al., 1999.

Qualquer que seja a escolha, e elas não são excludentes, seria ótimo futuramente vir a ter algo como um índice brasileiro de Orientação para o Mercado Externo. Quem sabe a existência de tal índice induza os produtores de bens e serviços a apurar seus esforços rumo ao mercado externo. Muito útil seria dispor de metodologia uniforme e independente de avaliação de Orientação para o Mercado Externo, que poderia ser aplicada em distintos períodos de tempo, permitindo identificar aspectos organizacionais que precisam ser melhorados em diferentes setores da economia. A metodologia, por sua vez, facilitaria a atuação de associações e federações empresariais e permitiria ao governo implementar políticas dirigidas a cada setor ou mesmo modificar sua estratégia de fomento às exportações. Ainda que leve tempo a consolidação de tal índice, espera-se que a iniciativa aqui exposta, mesmo sendo de mínima envergadura, possa estimular esforços adicionais de pesquisa nesse rumo tão promissor.

Por fim, resta mencionar as limitações desta pesquisa: a) a baixa taxa de resposta, que traz como limitação a representação da população (observou-se que mais da metade da amostra é composta por grandes empresas exportadoras de bens industriais); b) a falta de pesquisas brasileiras para comparação direta com os resultados aqui obtidos; c) a possibilidade de má interpretação dos respondentes; d) as possíveis diferenças entre as percepções dos respondentes e a realidade; e) o tamanho da amostra, que não permitiu uma análise confirmatória. Decerto a superação de tais limitações são avenidas a serem percorridas por pesquisas futuras.

\section{Artigo recebido em 17.04.2003. Aprovado em 09.02.2004.}


Referências Bibliográficas

CADOGAN, J.;

DIAMANTOPOULOS, A.

Narver and Slater, Kohli and Jaworski and the market orientation construct: integration and internationalization. Journal of Strategic Marketing, [S.I], v.3, p.41-60, 1995.

CADOGAN, J.;

DIAMANTOPOULOS, A.

MORTANGES, C.

A measure of Export Market Orientation: scale development and cross-cultural validation. Journal of International Business Studies, Washington, v.30, n.4, p.689-707, 1999.

CAMPBELL, D.

FISKE, D.

Convergent and discriminant validation by the multitraitmultimethod matrix. Psychological Bulletin, Washington v.56, n.2, p.81105, 1959.

\section{CHURCHILL, G. A.}

A paradigm for developing better measures of marketing constructs. Journal of Marketing Research, Chicago, v.16, n.1 , p.64-73, 1979.

\section{DALGIC, T.}

International marketing and market orientation: an early conceptual attempt at integration. Advances in International Marketing, Greenwich, v.6, p.69-82, 1994.
DESHPANDÉ, Rohit (Org.).

Developing a Market Orientation. Thousand Oaks: Sage Publications, 1999. 320p.

DIAMANTOPOULOS, A.

CADOGAN, J.

Internationalizing the market orientation construct: an in-depth interview approach. Journal of Strategic Marketing, [S.l], v.4, p. 2352, 1996.

HAIR, J. et al.

Multivariate Data Analysis. 5 ed. Prentice Hall: Upper Saddle River, 1999.

JAWORSKI, B.;

KOHLI, A.

Market Orientation: antecedents and consequences. Journal of Marketing, Nova Iorque, v.57, n.3, p. 53-70, 1993.

KOHLI, A.;

JAWORSKI, B.

Marketing Orientation: the construct, research propositions and managerial implications. Journal of Marketing, Nova Iorque, v.54, n.2, p.1-18, 1990.

\section{MALHOTRA, N. K.}

Marketing research: an applied orientation. 3 ed. New Jersey: Prentice Hall, 1999. 
MINISTÉRIODODESENVOLVIMENTO, INDÚSTRIA E COMÉRCIO EXTERIOR.

Site da organização. Disponível em $<$ http://www.mdic.gov.br> Acesso em janeiro/2002.

NAVER, J.;

SLATER, S.

The effect of Market Orientation on business profitability. Journal of Marketing, Nova Iorque, v.54, n.4, p.20-35, 1990.
PAPAGEORGIOU, D.;

MICHAELY, M.;

CHOKSI, A. (org.).

Liberalizing foreign trade: Brazil, Colombia and Peru. [S.I]:Basil Blackwell, v.4, 1991. .

THORSTENSEN, V. et al.

O Brasil frente a um mundo dividido em blocos. São Paulo: Nobel, 1994. 


\section{Apêndice: Constructos e Variáveis Mensuradas de Orientação para o Mercado Externo}

\section{Inteligência de Exportação}

1. Nós periodicamente revisamos os prováveis efeitos das mudanças no ambiente para o qual exportamos (p. ex. tecnologia, regulação).

2. As pessoas do departamento de produção interagem diretamente com os clientes para os quais exportamos para aprender como servi-los melhor.

3. Nós somos lentos em detectar mudanças nas preferências dos clientes estrangeiros em relação a produtos. (-)

4. Nós fazemos pesquisas com os usuários finais uma vez por ano para verificar a qualidade de nossos produtos e serviços.

5. Nós somos lentos em detectar mudanças no nosso ambiente de exportação (p. ex. tecnologia, regulação, economia). (-)

6. Nesta empresa, nós geramos muitas informações sobre as tendências (p. ex. regulação, desenvolvimento tecnológico, política, economia) nos mercados para os quais exportamos.

7. Nós geramos muitas informações com vistas a compreender as forças que influenciam as necessidades e preferências de nossos clientes estrangeiros.

8. Nós não geramos informações confiavéis/relevantes e suficientes sobre as atividades de nossos concorrentes nos mercados externos. (-)

9. Nós constantemente monitoramos nosso nível de comprometimento e orientação para servir às necessidades dos clientes para os quais exportamos.

10. Nossos dirigentes de todas as funções visitam regularmente os clientes atuais e prospectivos para os quais exportamos.

11. Nós medimos a satisfação dos clientes para os quais exportamos sistemática e regularmente.

\section{Disseminação de Informações}

12. Nós temos encontros "interfuncionais” pelo menos a cada trimestre para discutir tendências e desenvolvimentos (p. ex. regulação, tecnologias) nos mercados para os quais exportamos.

13. O pessoal do marketing da nossa empresa discute as necessidades futuras dos clientes para os quais exportamos com outros departamentos.

14. Nossa empresa periodicamente faz circular documentos (p. ex. relatórios, boletins internos) que fornecem informações sobre os clientes para os quais exportamos. 
15. Há uma comunicação mínima entre os departamentos de produção e exportação no que concerne ao desenvolvimento de mercados externos (p. ex. regulação, tecnologia). (-)

16. Quando um departamento encontra algo importante sobre nossos concorrentes em mercados externos, este é lento em alertar outros departamentos. (-)

17. Informações importantes sobre nossos concorrentes externos ficam frequentemente perdidas em nossos sistemas de trabalho. (-)

18. Nesta empresa, o pessoal de exportação raramente transmite informações sobre as preferências de nossos clientes às demais funções ou unidades. (-)

19. As informações sobre as atividades dos concorrentes externos frequentemente chegam às pessoas devidas tarde demais para ser de qualquer uso. (-)

20. As informações importantes sobre as tendências dos mercados para os quais exportamos (p. ex. regulação, tecnologia) são geralmente descartadas ao longo da cadeia de comunicação. (-)

21. As informações importantes sobre os clientes para os quais exportamos são disseminadas para baixo, até a base da empresa.

22. O pessoal diretamente envolvido nas operações de exportação fre- quentemente discute as atividades dos concorrentes externos com o pessoal não diretamente envolvido.

23. O pessoal de vendas da área de exportação raramente compartilha suas experiências com clientes com outras pessoas da empresa. (-)

24. Muitas informações sobre os nossos concorrentes externos são descartadas antes de chegar aos tomadores da decisão. (-)

25. Toda informação sobre nossos concorrentes externos é compartilhada dentro desta empresa.

26. As informações que podem influenciar a maneira como servimos os clientes para os quais exportamos demora demais para chegar ao pessoal da exportação. (-)

27. O pessoal da exportação regularmente troca informações em nossa empresa sobre as estratégias dos concorrentes externos.

28. Nós livremente trocamos informações, entre todas as áreas funcionais, sobre as experiências de sucesso ou insucesso relativas aos clientes estrangeiros.

29. Nossos dirigentes regularmente discutem as forças e fraquezas dos nossos concorrentes de exportação. 


\section{Responsividade}

30. Leva-se tempo demais nesta empresa para responder às mudanças de preços dos concorrentes nos mercados para os quais exportamos. (-)

31. Por uma ou outra razão nós tendemos a ignorar as mudanças das necessidades de produtos e serviços dos nossos clientes estrangeiros. (-)

32. Nós periodicamente revemos os esforços de desenvolvimento de produtos para assegurar que eles estejam alinhados com o que desejam nossos clientes estrangeiros.

33. A nossa estratégia de padronizar ou adaptar as nossos ofertas de produtos de exportação é baseada em detalhada pesquisa sobre o cliente.

34. Vários departamentos se reúnem periodicamente para planejar a resposta às mudanças que ocorrem no ambiente externo (p. ex. regulação, tecnologia).

35. As linhas de produtos que vendemos nos mercados externos dependem mais das nossas políticas internas do que das reais necessidades do mercado. (-)

36. Se um grande concorrente lançasse uma campanha intensa dirigida aos nossos clientes externos, nós implementaríamos uma resposta imediatamente.

37. As reclamações dos clientes ex- ternos não são ouvidas nesta empresa. (-)

38. Nós somos rápidos em responder a mudanças significativas da estrutura de preços dos nossos concorrentes em mercados externos.

39. Quando nós descobrimos que os clientes externos estão insatisfeitos com a qualidade do nosso serviço, nós tomamos medidas corretivas imediatamente.

40. Nós somos rápidos em responder a mudanças no nosso ambiente de exportação (p. ex. regulação, tecnologia, economia).

41. Todos os departamentos da nossa empresa estão envolvidos na implementação das estratégias para mercados externos.

42. Nossas estratégias de exportação são orientadas por nossas crenças sobre como podemos criar maior valor para os clientes externos.

43. Nós damos muita atenção aos serviços pós-venda em nossos mercados de exportação.

44. Nossos objetivos de exportação são dirigidos principalmente à satisfação do cliente.

45. Nós respondemos rapidamente a ações dos concorrentes que ameaçam nossos mercados externos.

46. Nossa estratégia de exportação para obter vantagem competitiva é baseada em nossa compreensão das necessidades dos clientes externos. 


\section{Mecanismo de Coordenação}

47. Os departamentos em nossa empresa trabalham juntos, como equipe, em relação aos nossos negócios de exportação.

48. As atividades das nossas áreas funcionais (p. ex. marketing/vendas, produção, $\mathrm{P} \& \mathrm{D}$, finanças,...) são integradas na busca de uma meta comum.

49. Na nossa empresa há conflitos interdepartamentais. (-)

50. Na nossa empresa, departamentos/indivíduos competem entre si para atingir seus próprios objetivos, mais do que trabalham juntos para atingir objetivos comuns. (-)

51. As pessoas chaves das áreas funcionais (p. ex. produção, finanças) atrapalham as atividades relacionadas à exportação desta empresa. (-)

52. Na nossa empresa, os objetivos buscados pelo pessoal da exportação não coincide com aqueles buscados pelo pessoal de produção e pesquisa e desenvolvimento.(-)

53. As pessoas chaves de outras áreas (p. ex. produção, finanças) apóiam aquelas envolvidas nas operações de exportação da empresa.

54. O pessoal da área de exportação constrói fortes relacionamentos com outras pessoas da nossa empresa.
55. O pessoal de vendas trabalha junto com outras áreas da empresa para tratar dos problemas de pósvenda e serviços em nossos mercados externos.

56. Na nossa empresa, quando ocorrem conflitos entre áreas funcionais (p. ex. produção e exportação), nós chegamos a acordos mutuamente satisfatórios.

57. Os funcionários da unidade de exportação e aqueles de outras áreas funcionais (p. ex. engenharia) ajudam-se.

58. Os funcionários envolvidos nas operações de exportação da nossa empresa preocupam-se uns com os outros assim como com eles próprios.

59. Além do pessoal de exportação, pode-se dizer que poucas pessoas nesta empresa contribuem para o sucesso das atividades de exportação. (-)

60. Algumas pessoas chaves da nossa empresa dão pouca importância às nossas atividades de exportação. (-)

61. As atividades de exportação desta empresa são dificultadas pelo comportamento de alguns gerentes de outros departamentos (p. ex. produção). (-)

62. Nesta empresa, há um senso de trabalho em equipe que vai até a base da hierarquia. 
63. Há forte relacionamento de trabalho cooperativo entre o pessoal da produção e da exportação.

64. As diferentes áreas funcionais desta empresa trabalham juntas na mesma direção.

65. Nós resolvemos questões e conflitos por meio da comunicação e solução de problemas em grupo.

66. Na nossa empresa, considera-se que quanto menos interação o pessoal da área de exportação tiver com outras áreas, melhor é. (-)

67. As pessoas de diferentes áreas em nossa empresa discutem seus problemas aberta e construtivamente.

68. Há tensões entre as diferentes áreas (p. ex. exportação e produção) que interferem nas atividades exportadoras da empresa. (-)
69. Nesta empresa, as funções (p. ex. exportação e produção) são integradas para servir às necessidades de nossos mercados externos.

70. Nossos gerentes compreendem como cada um em nosso negócio pode contribuir para criar valor para os clientes externos.

71. Nesta empresa, o pessoal de exportação compartilha programas e recursos com outras áreas funcionais.

\section{Itens de Validação}

72. Nós somos eficientes em gerar informações sobre todos os aspectos dos mercados para os quais exportamos.

73. Nós somos eficientes em disseminar as informações relativas às exportações em nossa empresa.

74. Nós somos muito eficientes em responder a mudanças em nossos mercados de exportação.

75. As atividades e os indivíduos são coordenados em nossa empresa.

(-) Estes itens são negativos e foram devidamente recodificados antes da análise de dados. 